\title{
A Novel Power ReduCtion TeCHNIQUe For DuAL-THRESHOLD DOMINO LOGIC IN SUB-65NM TECHNOLOGY
}

\author{
Tarun Kr. Gupta ${ }^{1}$ and Kavita Khare ${ }^{2}$ \\ Department of Electronics and Communication Engineering, MANIT, Bhopal, India \\ tarunieterediffmail.com ${ }^{1}$, kavita_khareleyahoo.co.in ${ }^{2}$
}

\begin{abstract}
A novel technique for dual- threshold is proposed and examined with inputs and clock signals combination in $65 \mathrm{~nm}$ dual- threshold footerless domino circuit for reduced leakage current. In this technique a p-type and an n-type leakage controlled transistor (LCTS) are introduced between the pull-up and pull-down network and the gate of one is controlled by the source of the other. A high-threshold transistor is used in the input for reducing gate oxide leakage current which becomes dominant in nanometer technology. Simulations based on 65nm BISM4 model for proposed domino circuits shows that CLIL (clock low and input low) and CHIH (clock high and input high) state is ineffective for lowering leakage current. The CLIH (clock low input high) state is only effective to suppress the leakage at low and high temperatures for wide fan-in domino circuits but for AND gate CHIL (clock high input low) state is preferred to reduce the leakage current. The proposed circuit technique for AND2, OR2, OR4 and OR8 circuits reduces the active power consumption by $39.6 \%$ to $57.9 \%$ and by $32.4 \%$ to $40.3 \%$ at low and high die temperatures respectively when compared to the standard dual-threshold voltage domino logic circuits.
\end{abstract}

\section{KEYWORDS}

Dual-Threshold, Domino logic, Subthreshold leakage, Gate oxide tunneling, Leakage current.

\section{INTRODUCTION}

As a common logic in high-speed performance chip design, domino circuits are widely used and can be classified into footerless and footed domino [1-3]. The footed domino has better timing characteristics because the footer transistor isolates the pull-down network (PDN) from ground during precharge phase so the dynamic node does not discharge through the PDN. In footerless dominos circuit evaluation delay is reduced and consumes less power. Owing different characteristics the footerless and footed dominos both are extensively used in high microprocessors. In a multistage domino, the first stage is typically footed and the others in chain are footerless [3].

With aggressive scaling of CMOS device reduces the threshold voltage $\left(\mathrm{V}_{t}\right)$ accompanies with the exponential increase of subthreshold leakage current $\left(\mathrm{I}_{\text {sub }}\right)$ which is a concern not only for leakage power consumption but also for noise immunity. For solving $\mathrm{I}_{\text {sub }}$ problem many techniques at circuit level have been proposed which includes input vector control [4], body-bias control [5], dual- $\mathrm{V}_{\mathrm{t}}[6]$, transistor-stack effect [7] and so on.

In fact, $\mathrm{I}_{\mathrm{gate}}$ increases exponentially with the scaling of oxide thickness $\left(\mathrm{t}_{\mathrm{ox}}\right) .2003$ International Technology Roadmap for Semiconductor (ITRS) predicts that $t_{\mathrm{ox}}$ will decrease from $13 \AA$ for the $65 \mathrm{~nm}$ generation to $9 \AA$ for $35 \mathrm{~nm}$ [8]. With such thin $\mathrm{t}_{\mathrm{ox}}$, accordingly, $\mathrm{I}_{\mathrm{gate}}$ is becoming a 
significant contributor to the total leakage current as CMOS process advances to sub-65nm regime. The probability of electron tunneling is much higher than the probability of hole tunneling through the silicon- dioxide used as gate oxide in bulk CMOS technology. Simulation results shows that $I_{\text {gate }}$ of a PMOS device is much lower when compared with $I_{\text {gate }}$ of NMOS device as shown in Fig. 1 with similar physical dimensions (width, length and $t_{\mathrm{ox}}$ ) in a $65 \mathrm{~nm}$ technology and at the same potential difference across the gate insulator. The $\mathrm{I}_{\text {gate }}$ produced by an NMOS transistor is 81.5 times higher at supply voltage $1.2 \mathrm{~V}$ and 16 times higher at supply voltage of $0.2 \mathrm{~V}$ when compared with PMOS transistor. The difference of $\mathrm{I}_{\text {gate }}$ between NMOS and PMOS transistor is increased with increase of supply voltage as illustrated in Fig. 1. During ideal mode or at low temperature most of the power consumption occurs due to $\mathrm{I}_{\text {gate }}$ and during nonideal mode or at high temperature most of the power is consumed by the $\mathrm{I}_{\text {sub }}$. So new circuit technique should be efficient enough to reduce the $I_{\text {gate }}$ and $I_{\text {sub }}$ at low and high temperatures respectively.

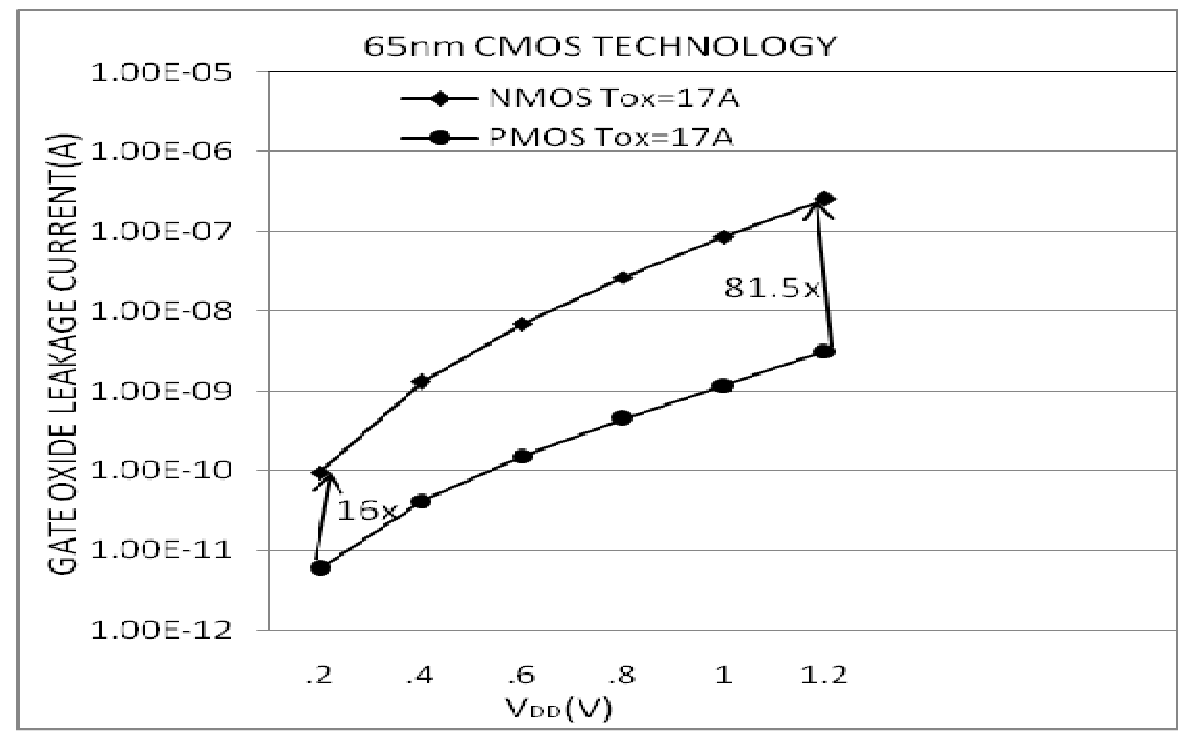

Figure 1. Comparison of gate oxide leakage current produced by a NMOS and PMOS transistors with same physical dimensions.

Kao et al. [6] indicated that high clock and high input $(\mathrm{CHIH})$ signals are preferable to reduce $\mathrm{I}_{\text {sub }}$ in sleep mode dual- $\mathrm{V}_{\mathrm{t}}$ footerless domino gate. However, the $\mathrm{CHIH}$ sleep state produces great gate oxide leakage current $\left(\mathrm{I}_{\mathrm{gate}}\right)$ through the PDN transistors in both footed and footerless dominos. The most recent, comprehensive analysis of the total leakage at $65 \mathrm{~nm}$ including $\mathrm{I}_{\text {sub }}$ and $\mathrm{I}_{\text {gate }}$ of footerless dominos was carried out by Z. Liu et al. [9]. Considering the impact of $\mathrm{I}_{\text {gate }}$ on the total leakage current, the study indicates that high clock and low input (CHIL) state is preferable in dual- $\mathrm{V}_{\mathrm{t}}$ footerless dominos, particularly at low sleep temperatures.

In this paper, a new circuit technique is proposed which reduces the $I_{\text {gate }}$ and $I_{\text {sub }}$ leakage current with inputs and clock signal combination. The proposed circuit consumes less active power for low and high die temperatures but with more delay and area overhead compared with standard dual-threshold $\left(\right.$ dual- $\left.\mathrm{V}_{\mathrm{t}}\right)$ domino logic circuit.

The paper is organized as follows: Section 2 characterizes leakage current in domino circuit are surveyed. In Section 3 the proposed lector dual $-\mathrm{V}_{\mathrm{t}}$ domino circuit is explained. Simulation results are given in Section 4 following the conclusion in Section 5. 


\section{Characteristics of Leakage Current in Domino Circuit}

This section is divided into two subsections namely 2.1 and 2.2. In Section 2.1 comparison of sub threshold and gate oxide leakage current produced by PMOS and NMOS transistors for low- $\mathrm{V}_{t}$ and high- $\mathrm{V}_{\mathrm{t}}$ is shown. In Section 2.2 working of standard dual- $\mathrm{V}_{\mathrm{t}}$ domino is discussed.

\section{1. $I_{\text {sub }}$ and $I_{\text {gate }}$ current analysis of a single transistor}

Maximum gate oxide leakage and sub threshold leakage currents produced by PMOS and NMOS is shown in Fig. 2. In Fig. 2(a) four components of $I_{\text {gate }}$ are shown: Gate to channel tunneling current $\left(\mathrm{I}_{\mathrm{gc}}\right)$, gate-to-source tunneling current $\left(\mathrm{I}_{\mathrm{gs}}\right)$, gate-to-drain tunneling current $\left(\mathrm{I}_{\mathrm{gd}}\right)$ and gateto-body tunneling current $\left(\mathrm{I}_{\mathrm{gb}}\right)$ [9]. $\mathrm{I}_{\mathrm{gs} \text { and }} \mathrm{I}_{\mathrm{gd}}$ are the edge tunneling currents from gate to source and drain terminals respectively, through the gate-to-source and gate-to-drain overlap areas. $\mathrm{I}_{\mathrm{gc}}$ is shared between source and drain terminals [10]. $\mathrm{I}_{\mathrm{gb}}$ is smaller than the other three components of gate tunneling current and it is typically several orders of magnitude.

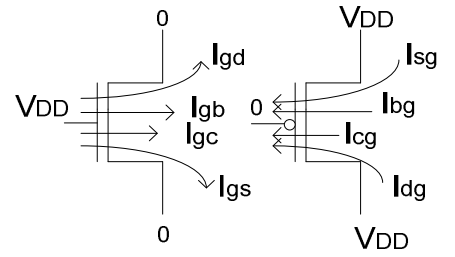

(a)

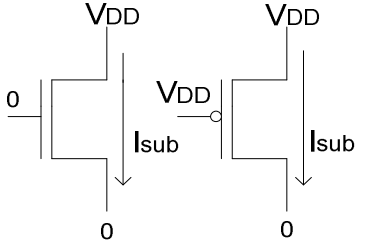

(b)

Figure 2. State of maximum gate oxide and subthresold leakage current, in NMOS and PMOS transistors. (a) Maximum gate oxide leakage current state. (b) Maximum subthresold leakage current state.

As shown in Fig. 2(a) maximum gate oxide leakage current flows when the transistor is turned $\mathrm{ON}$ and maximum potential difference between gate-to-source and gate-to-drain terminals. As shown in Fig. 2(b) maximum sub threshold leakage current flows when the transistor is turned $\mathrm{OFF}$ and maximum the potential difference between source and drain terminals.

A comparison of normalized gate oxide and subthreshold leakage currents produced by NMOS and PMOS transistors for low- $V_{t}$ and high- $V_{t}$ in a $65 \mathrm{~nm}$ dual- $V_{t}$ CMOS technology is listed in Table 1 . The data are measured for low and high die temperatures.

Table 1. Normalized gate oxide and subthreshold leakage currents for NMOS and PMOS (low-V and high- $\mathrm{V}_{\mathrm{t}}$ ) transistors at low and high die temperatures.

\begin{tabular}{|l|c|c|c|c|}
\hline & \multicolumn{2}{|c|}{ NMOS Transistor } & \multicolumn{2}{c|}{ PMOS Transistor } \\
\hline & Low-V & High-V & How-V & High-V $_{\mathbf{t}}$ \\
\hline $\mathbf{I}_{\text {sub }}\left(\mathbf{1 1 0}^{\mathbf{0}} \mathbf{C}\right)$ & 1.53 & 1.98 & 1.16 & 1 \\
\hline $\mathbf{I}_{\text {gate }}\left(\mathbf{1 1 0}^{\mathbf{0}} \mathbf{C}\right)$ & .89 & .098 & .011 & .0003 \\
\hline $\mathbf{I}_{\text {sub }}\left(\mathbf{2 5}^{\mathbf{0}} \mathbf{C}\right)$ & 1.18 & 1.41 & 1.17 & 1 \\
\hline $\mathbf{I}_{\text {gate }}\left(\mathbf{2 5}^{\mathbf{0}} \mathbf{C}\right)$ & 2.61 & .29 & .036 & .0011 \\
\hline
\end{tabular}

Transistor Length $=65 \mathrm{~nm}$, Width $=1 \mu \mathrm{m}$, Low $-\mathrm{V}_{\mathrm{t}}=0.22 \mathrm{~V}$, High $-\mathrm{V}_{\mathrm{t}}=0.423 \mathrm{~V}, \mathrm{~V}_{\mathrm{DD}}=1 \mathrm{~V}$. For each temperature, leakage currents are normalized by subthreshold leakage current produced by a high- $\mathrm{V}_{\mathrm{t}}$ PMOS transistor.

Firstly, the $\mathrm{I}_{\text {gate }}$ produced by a low- $\mathrm{V}_{\mathrm{t}}$ NMOS is $81 \mathrm{x}$ and $72.5 \mathrm{x}$ higher than the $\mathrm{I}_{\text {gate }}$ produced by a low- $\mathrm{V}_{\mathrm{t}}$ PMOS at $110^{\circ} \mathrm{C}$ and $25^{\circ} \mathrm{C}$ respectively, as illustrated in Table 1 . It shows that the probability of hole tunneling is much smaller than the probability of electron tunneling through 
the gate insulator. Therefore, the $\mathrm{I}_{\text {gate }}$ produced by a PMOS device is much smaller than the $\mathrm{I}_{\text {gate }}$ produced by a NMOS device with similar physical dimensions (width, length and $\mathrm{t}_{\mathrm{ox}}$ ) in a $65 \mathrm{~nm}$ technology and at the same potential difference across the gate insulator [11].

Secondly, the $\mathrm{I}_{\text {gate }}$ produced by a low- $\mathrm{V}_{\mathrm{t}} \mathrm{NMOS}$ is $9.1 \mathrm{x}$ at $110^{\circ} \mathrm{C}$ and $9 \mathrm{x}$ at $25^{\circ} \mathrm{C}$ higher than $\mathrm{I}_{\text {gate }}$ by a high- $\mathrm{V}_{\mathrm{t}}$ NMOS transistor. Relatively higher gate tunneling barrier for the electrons is exploited in this paper by using a high- $\mathrm{V}_{\mathrm{t}} \mathrm{NMOS}$ transistor at the input of a domino circuits to reduce the gate oxide leakage current overhead of the proposed dual- $\mathrm{V}_{\mathrm{t}}$ domino circuit technique.

\subsection{Standard Dual- $V_{t}$ Domino Logic}

The standard dual- $\mathrm{V}_{\mathrm{t}}$ domino logic is shown in Fig.3. The first dual- $\mathrm{V}_{\mathrm{t}}$ domino logic circuit was proposed by Kao [12] employing dual- $\mathrm{V}_{\mathrm{t}}$ transistors for reduction of subthreshold leakage circuit. For maintaining the same delay as in standard footerless domino circuit the critical signal transition should occur through low- $\mathrm{V}_{\mathrm{t}}$ during evaluation phase. Alternatively, during precharge phase signal transition is not a critical issue for maintaining in the performance of the circuit and the transistors that are active during precharge phase having high- $\mathrm{V}_{t}$ transistor [13]. The feedback keeper transistor parallel with precharge transistor whose gate is biased with the output voltage is employed to maintain the dynamic voltage against coupling noise, charge sharing problem and subthreshold leakage current [14].

The working of standard dual- $\mathrm{V}_{\mathrm{t}}$ domino circuit is as follows: When the clock is low the prechrage transistor $\mathrm{MP}_{1}\left(\right.$ high $\left.-\mathrm{V}_{\mathrm{t}}\right)$ is $\mathrm{ON}$ and charges the dynamic node, this phase is called precharge phase. During the precharge phase output node goes low and $\mathrm{MP}_{2}\left(\right.$ high- $\left.\mathrm{V}_{\mathrm{t}}\right)$ transistor turns ON maintaining the dynamic node in the high state. The output of the domino logic is independent of the inputs applied at the evaluation network only the leakage current is dependent on the input vectors applied. Now when the clock is high transistor, $\mathrm{MP}_{1}$ is $\mathrm{OFF}$ and transistor $\mathrm{MP}_{2}$ is dependent on the output of the domino circuit, this phase is called evaluation phase. The dynamic node charging will depend on the input vectors applied and according to that output node will be low or high. The subthreshold and gate oxide leakage will also depend on the applied input vectors.

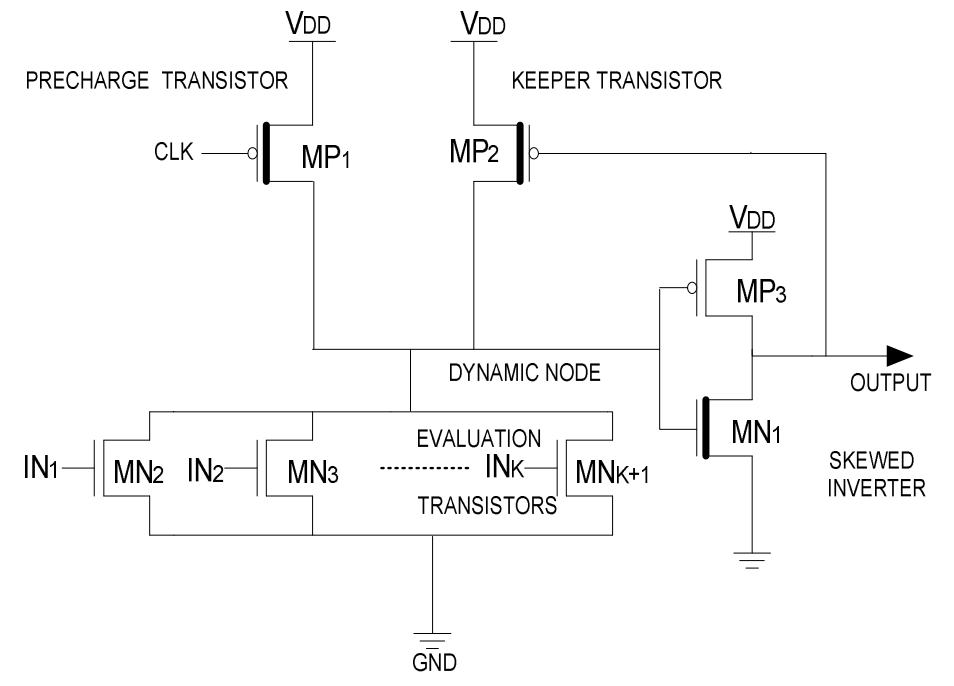

Figure 3. Standard Dual- $\mathrm{V}_{\mathrm{t}}$ Domino Logic OR Gate. High- $\mathrm{V}_{\mathrm{t}}$ transistors are represented by thick line in channel region. 


\section{LECTOR DUAL - V $\mathrm{T}_{\mathrm{T}}$ DOMINO LogIC}

The proposed circuit technique effectively enhances the reduction of subthreshold and gate oxide leakage simultaneously. The proposed circuit is illustrated in Fig.4. The concept behind the approach is the reduction of leakage power using the effective stacking of transistor between the path from supply voltage to ground. The observation is based on [15], [16] and [17] in which a state with only one transistor is OFF between the supply voltage and ground is more leaky then the state with more than one transistor is off in a path from supply voltage to ground.

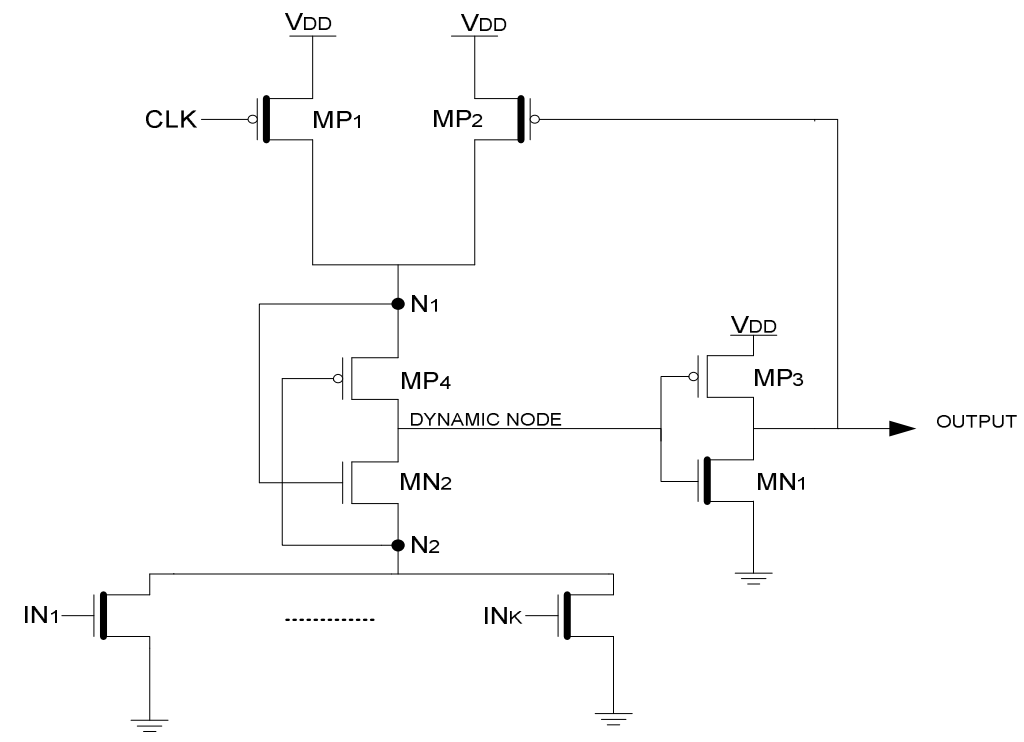

Figure 4. Proposed Lector Dual- $\mathrm{V}_{\mathrm{t}}$ Domino Logic OR Gate. High- $\mathrm{V}_{\mathrm{t}}$ transistors are represented by thick line in channel region.

In our approach a low- $\mathrm{V}_{\mathrm{t}} \mathrm{MP}_{4}$ (PMOS) and $\mathrm{MN}_{2}$ (NMOS) LCTs are introduced between the precharge and evaluation network and the gate of these transistors are controlled by the source of each other. The drain node of $\mathrm{MP}_{4}$ and $\mathrm{MN}_{2}$ are connected together to form the input of the inverter. In this configuration, transistor $\mathrm{MP}_{4}$ and $\mathrm{MN}_{2}$ switching will depend on the voltage potential at node $\mathrm{N}_{2}$ and $\mathrm{N}_{1}$ respectively. So for any combination of input in the pull-down network one of the LCT will operate near its cut-off region and increase the resistance between $\mathrm{V}_{\mathrm{DD}}$ and ground rails leads to the reduction of leakage current. High- $\mathrm{V}_{t}$ NMOS transistors replaces the low- $\mathrm{V}_{\mathrm{t}}$ input transistors of pull-down network to reduce the gate oxide leakage current.

The proposed domino gate operates similar to standard dual- $\mathrm{V}_{\mathrm{t}}$ domino gate. In proposed domino circuit when the clock signal turns low the dynamic node is charged high through the transistor $\mathrm{MP}_{1}\left(\right.$ high $\left.-\mathrm{V}_{\mathrm{t}}\right)$ and $\mathrm{MP}_{4}\left(\right.$ low- $\left.\mathrm{V}_{\mathrm{t}}\right)$. The charging of dynamic node is almost independent of the previous clock input state. Suppose if the inputs are low before the clock sets low then node $\mathrm{N}_{2}$ will be at low potential and transistor $\mathrm{MP}_{4}$ offers the less resistance path for charging of dynamic node or if the inputs are high before the clock sets low then the voltage at node $\mathrm{N}_{2}$ is not sufficient to turn $\mathrm{MP}_{4}$ completely to $\mathrm{OFF}$ state $\left(\mathrm{MP}_{4}\right.$ is operating near its cut off region). The resistance of $\mathrm{MP}_{4}$ will be lesser than in OFF resistance allowing the dynamic node to get charge high. The charging of the dynamic node is called precharging phase. In this case output of the domino circuit is independent of the inputs applied at the evaluation network only the leakage current is dependent on the input vectors applied, the combination of clock and inputs low clock and low input (CLIL) and low clock and high input (CLIH) is shown in Fig.5 and Fig.6 respectively. 
International Journal of VLSI design \& Communication Systems (VLSICS) Vol.4, No.1, February 2013

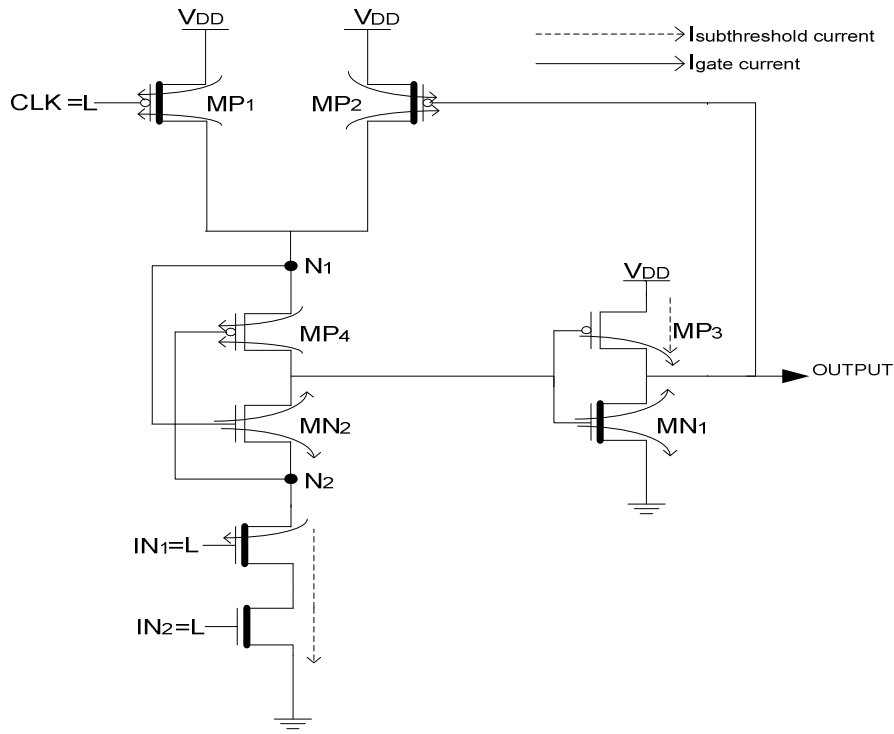

Figure 5. A two- input Lector Dual- $\mathrm{V}_{\mathrm{t}}$ domino AND gate in CLIL state. The most significant components of subthreshold and gate oxide leakage currents are illustrated with arrows. High- $\mathrm{V}_{\mathrm{t}}$ transistors are represented by thick line in channel region.

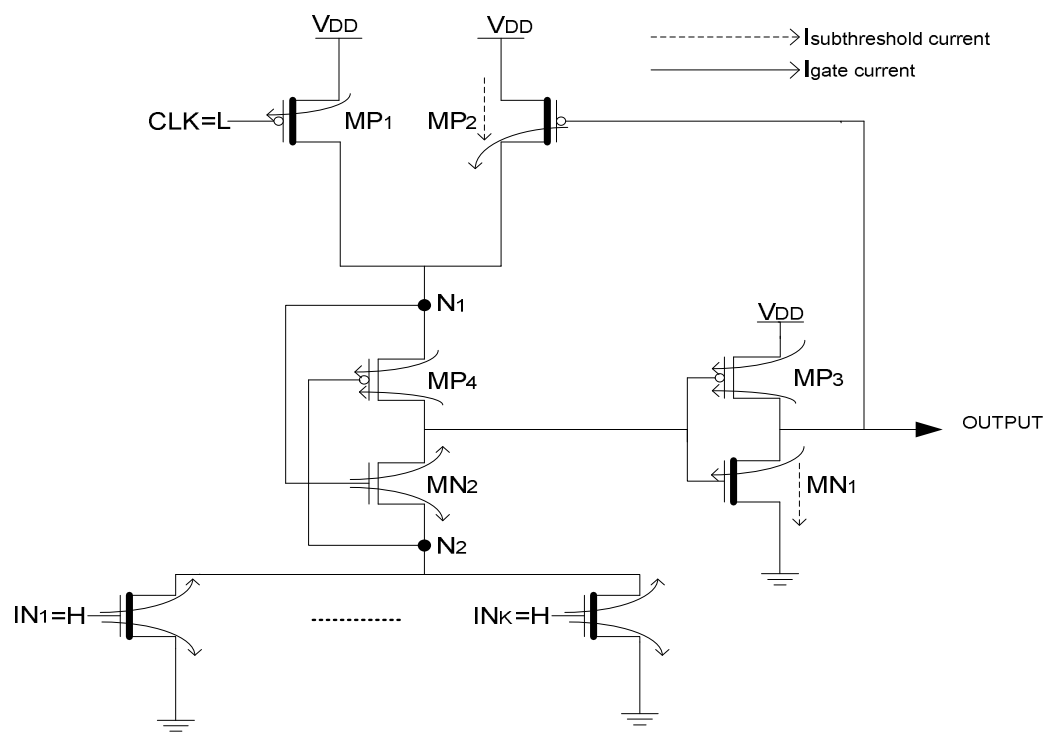

Figure 6. A k- input Lector Dual- $\mathrm{V}_{\mathrm{t}}$ domino OR gate in CLIH state. The most significant components of subthreshold and gate oxide leakage currents are illustrated with arrows. High- $\mathrm{V}_{t}$ transistors are represented by thick line in channel region.

Now when the clock turns high or standby mode this is called evaluation phase, depending on the inputs the dynamic node gets charged or discharged. If all the inputs are low the dynamic node will not be discharged by the evaluation network and the output of the inverter will be low and it turn ON the transistor $\mathrm{MP}_{2}\left(\right.$ high- $\left.\mathrm{V}_{\mathrm{t}}\right)$, the voltage at node $\mathrm{N}_{1}$ will turn $\mathrm{ON}$ the transistor $\mathrm{MN}_{1}$ (high- $\mathrm{V}_{\mathrm{t}}$ ) but the voltage induced at node $\mathrm{N}_{2}$ will not cut off the transistor $\mathrm{MP}_{4}$ it will operate near cut-off region offering high resistance path between $\mathrm{V}_{\mathrm{DD}}$ and ground reducing sub threshold and gate leakage current. In this CHIL sleep state as shown in Fig. 7 all the transistors in evaluation network exhibits both the $\mathrm{I}_{\text {sub }}$ and $\mathrm{I}_{\text {gate }}$ leakage current simultaneously. In this case $\mathrm{I}_{\text {sub }}$ dominates 
$\mathrm{I}_{\text {gate }}$ therefore CHIL is not a leakage reduction sleep state for the proposed circuits. For other sleep state $\mathrm{CHIH}$ as shown in Fig. 8 the dynamic node will be discharged through the evaluation network and the output of the inverter will be high. Transistor $\mathrm{MP}_{2}$ will turn OFF, the voltage at node $\mathrm{N}_{1}$ will operate the transistor $\mathrm{MN}_{2}$ near its cut off region again offering high resistance path. The potential at node $\mathrm{N}_{2}$ will turn $\mathrm{ON}$ the transistor $\mathrm{MP}_{4}$. So by introducing the low- $\mathrm{V}_{\mathrm{t}}$ LCTs the resistance between $\mathrm{V}_{\mathrm{DD}}$ and ground is increased and simultaneously propagation delay of the domino circuit is also increased. The propagation delay will be controlled by sizing of the LCTs. Lector stacking retains the logic state during standby mode as in the standard dual- $\mathrm{V}_{\mathrm{t}}$ domino logic. In CHIH only $\mathrm{I}_{\text {gate }}$ flows through the evaluation transistors and therefore this is the leakage reduction state in standby mode.

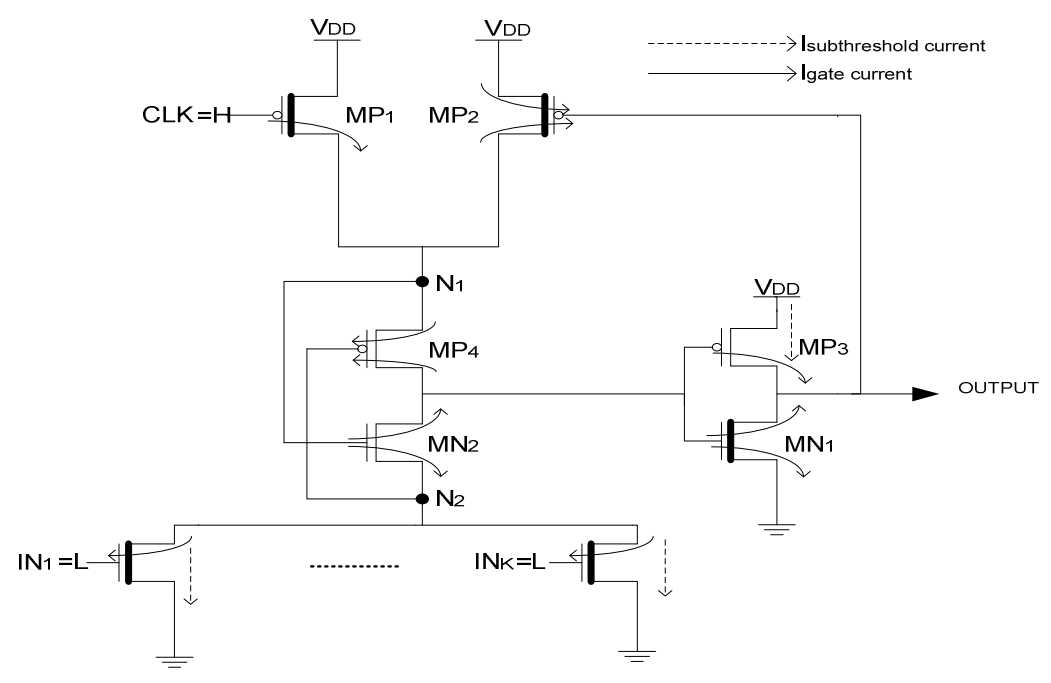

Figure 7. A k- input Lector Dual- $\mathrm{V}_{\mathrm{t}}$ domino OR gate in CHIL state. The most significant components of subthreshold and gate oxide leakage currents are illustrated with arrows. High- $\mathrm{V}_{t}$ transistors are represented by thick line in channel region.

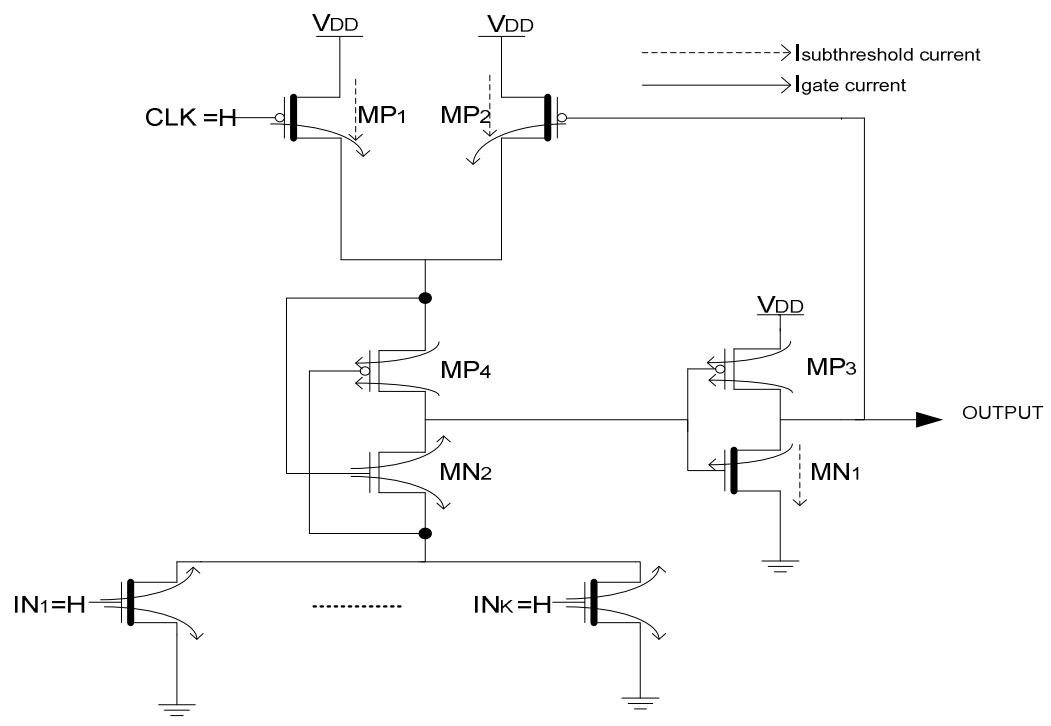

Figure 8. A k- input Lector Dual- $\mathrm{V}_{\mathrm{t}}$ domino OR gate in CHIH state. The most significant components of subthreshold and gate oxide leakage currents are illustrated with arrows. High- $\mathrm{V}_{\mathrm{t}}$ transistors are represented by thick line in channel region. 


\section{Simulation Results}

BISM4 device model [18] is used for simulating the standard dual- $\mathrm{V}_{\mathrm{t}}$ domino logic and proposed technique circuits for accurate estimation of subthreshold and gate oxide leakage currents. Following currents are simulated in a $65 \mathrm{~nm}$ CMOS technology $\left(\mathrm{V}_{\text {tnlow }}=\left|\mathrm{V}_{\text {tplow }}\right|=0.22 \mathrm{~V}\right.$, $\mathrm{V}_{\text {tnhigh }}=0.423 \mathrm{~V},\left|\mathrm{~V}_{\text {tphigh }}\right|=0.365 \mathrm{~V}, \mathrm{~V}_{\mathrm{DD}}=1 \mathrm{~V}$ and output capacitance $\mathrm{C}_{\text {out }}=1 \mathrm{fF}$ ) 2-input domino AND gate (AND2), 2-input, 4-input and 8-input domino OR gates (OR2, OR4 and OR8 respectively) by the HSPICE tool [19-20]. All these circuits are designed with standard dual- $\mathrm{V}_{\mathrm{t}}$ domino and proposed dual- $\mathrm{V}_{\mathrm{t}}$ technique. To have a reasonable comparison the sizing of NMOS and PMOS are equal in both the technique circuits. For measuring active power consumption clock pulse of $30 \mathrm{~ns}$ is applied and measured for low and high inputs at low and high die temperatures. Comparison is done for total leakage power consumption in all the circuits by both the techniques during ideal and non ideal mode for low and high inputs at $25^{\circ} \mathrm{C}$ and $110^{\circ} \mathrm{C}$. The low and high input states covers all the worst-case scenario for leakage power consumption that fall in the intermediate state of inputs because the maximum number of OFF transistor will occur when all the inputs are low and minimum number of OFF transistor will occur when all the inputs are high.

\subsection{Active Power Consumption}

Active Power Consumption of the domino circuits are shown in Fig. 9 at $25^{\circ} \mathrm{C}$ and $110^{\circ} \mathrm{C}$. The result shows that active power in lector dual- $\mathrm{V}_{\mathrm{t}}$ circuits is reduced as compared with the standard dual- $\mathrm{V}_{\mathrm{t}}$ domino circuits. At $25^{\circ} \mathrm{C}$ the active power consumption decreases by $39.6 \%$ in AND2, $41.3 \%$ in OR2, $49.7 \%$ in OR4, $57.9 \%$ in OR8 and at $110^{\circ} \mathrm{C} 36.2 \%$ in AND2, 32.4\% in OR2, $40.3 \%$ in OR4, 38.5\% in OR8 when compared with standard dual- $\mathrm{V}_{\mathrm{t}}$ domino circuits. It is observed that lector dual- $\mathrm{V}_{\mathrm{t}}$ technique produces slightly weak logic levels due to which it leads to the reduction of active power consumption. Similarly, it is applicable for other domino circuits.

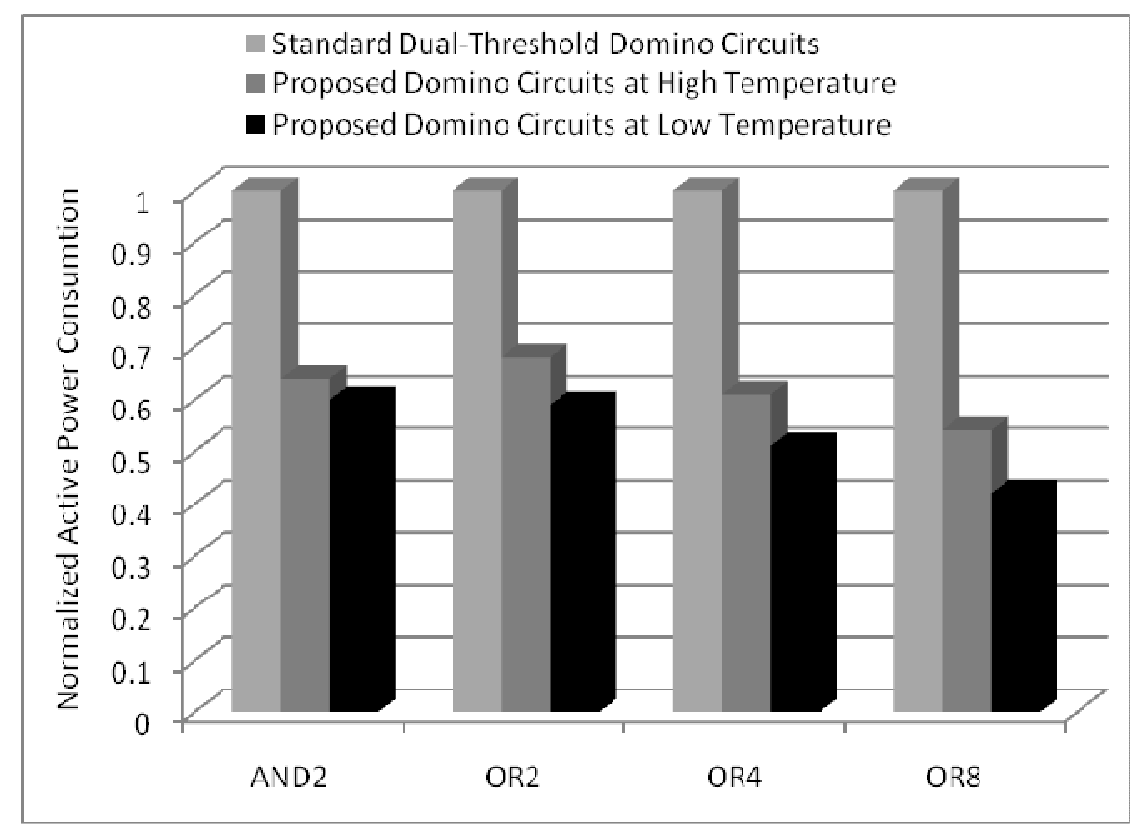

Figure 9. Active power consumption of two domino circuit techniques at $25^{\circ} \mathrm{C}$ and $110^{\circ} \mathrm{C}$. For each circuit power consumption is normalized to the power consumed by standard dual- $\mathrm{V}_{\mathrm{t}}$ domino technique. 


\subsection{Leakage Power Consumption at $25^{\circ} \mathrm{C}$}

In this part, it is assumed that sleep period is long and the sleep temperature has fallen to the room temperature. At low temperature in sub-65nm technology $\mathrm{I}_{\text {gate }}$ is dominant over $\mathrm{I}_{\text {sub }}$, based on simulation result for the proposed domino circuit as shown in Table 2, CHIL and CLIH states are preferred for reduction of leakage current.

Table 2. Leakage power saving at $25^{\circ} \mathrm{C}$ compared with standard dual- $\mathrm{V}_{\mathrm{t}}$ domino circuits

\begin{tabular}{|c|c|c|c|c|}
\hline & AND2 & OR2 & OR4 & OR8 \\
\hline CHIL & $83.79 \%$ & $43.86 \%$ & $46.25 \%$ & $50.52 \%$ \\
\hline CLIH & $69.7 \%$ & $69.3 \%$ & $73.2 \%$ & $92.68 \%$ \\
\hline
\end{tabular}

The proposed dual $\mathrm{V}_{\mathrm{t}}$ domino technique reduces the total leakage power by $43.86 \%$ to $83.79 \%$ for CHIL state and $69.3 \%$ to $92.68 \%$ for CLIH as compared with standard dual $\mathrm{V}_{t}$ domino circuits. Based on result analysis, CLIH state is most suitable for wide OR domino circuits at room temperature for low leakage power consumption but for AND gate best results obtained at CHIL state.

\subsection{Leakage Power Consumption at $110^{\circ} \mathrm{C}$}

In this part, it is assumed that the sleep mode is short and the temperature keeps $110^{\circ} \mathrm{C}$ during the short sleep period. At high temperature, $\mathrm{I}_{\text {sub }}$ is dominant over $\mathrm{I}_{\text {gate }}$, based on simulation result for the proposed domino circuits as shown in Table 3, same as at $25^{\circ} \mathrm{C}, \mathrm{CHIL}$ and CLIH states are preferred for reduction of leakage current.

Table 3. Leakage power saving at $110^{\circ} \mathrm{C}$ compared with standard dual- $\mathrm{V}_{\mathrm{t}}$ domino circuits

\begin{tabular}{|c|c|c|c|c|}
\hline & AND2 & OR2 & OR4 & OR8 \\
\hline CHIL & $66.7 \%$ & $11.42 \%$ & $18.1 \%$ & $24.5 \%$ \\
\hline CLIH & $50.83 \%$ & $57.4 \%$ & $65.68 \%$ & $72.73 \%$ \\
\hline
\end{tabular}

The proposed dual- $\mathrm{V}_{\mathrm{t}}$ domino techniques reduces the leakage power by $18.1 \%$ to $66.7 \%$ for CHIL state and $50.83 \%$ to $72.73 \%$ for CLIH state as compared to standard dual $\mathrm{V}_{\mathrm{t}}$ domino circuits. Based on simulation results, same as at $25^{\circ} \mathrm{C}$, CLIH state is suitable for wide fan-in domino circuits but for AND gate CHIL state shows the low leakage power consumption at high temperature.

\section{CONCLUSION}

In the sub-65nm technologies both the gate dielectric and subthreshold leakage currents must be suppressed for reducing power consumption. Therefore, a new domino technique is proposed for simultaneously reducing gate oxide and subthreshold leakage currents in domino logic circuits at different temperatures. 
The proposed domino circuit technique exploits the lector stacking effect employed between precharge and evaluation network and characteristics of high- $\mathrm{V}_{\mathrm{t}}$ NMOS transistors used as input transistors of domino circuits. Result shows reduction of active power by $39.6 \%$ to $57.9 \%$ at low and $32.4 \%$ to $40.3 \%$ at high die temperatures. At low and high temperature CLIH state is preferred for wide OR gates, proposed work improves the leakage power by $69.3 \%$ to $92.68 \%$ at low temperature and at high temperature the improvement in total leakage power by $58.83 \%$ to $72.73 \%$ when compared with standard dual- $\mathrm{V}_{\mathrm{t}}$ domino circuits. This technique can be used for very high speed low power applications.

\section{REFERENCES}

[1] H. Mahmoodi-Meimand, K. Roy, (2003) "A Leakage-tolerant high fan-in dynamic circuit style", IEEE International Systems-On-Chip Conference, pp. 117-120.

[2] J.-S.Wang, S.-j.Shieh, C.Yeh, Y.-h.Yeh, (2004) "Pseudo-footless CMOS domino logic circuits for high-performance VLSI designs", ISCAS, pp. 401-404.

[3] V. Kursun and E.G. Friedman, (2003) "Domino logic with variable threshold voltage keeper", IEEE Trans. Very Large Scale Integr. (VLSI) Syst., Vol. 11, No. 6, pp. 1080-1093.

[4] Abdollahi, F. Fallah, M. Pedram, (2004) "Leakage current reduction in CMOS VLSI circuits by input vector control”, IEEE Trans. Very Large Scale Integr. (VLSI) Syst., Vol.12, No. 2, pp. 140-153.

[5] A. Keshavarzi, S. Narendra, S. Borkar, C.F. Hawkins, K. Roy, V. De, (1999) "Technology scaling behavior of optimum reverse body bias for standby leakage power reduction in CMOS IC's", Int. Symposium on Low Power Electron. Design, pp. 252-254.

[6] J.T. Kao and A.P. Chandrakasan, (2000) "Dual-threshold voltage techniques for low-power digital circuits", IEEE Journal of Solid-State Circuits, Vol. 35, No. 7, pp. 1009-1018.

[7] S.Heo, K. Asanovic, (2002) "Leakage-biased domino circuits for dynamic fine-grain leakage reduction", Int. Symposium on VLSl Circuits Digest, pp. 316-319.

[8] International Technology Roadmap for Semiconductors, <http://public.itrs.net/>, accessed 2003.

[9] Z. Liu and V. Kursun, (2006) "Leakage power characteristics of dynamic circuits in nanometer CMOS technologies”, IEEE Trans. Circuits Syst. II, Exp. Briefs, Vol. 53, No. 8, pp. 692-696.

[10] H. Sasaki, M. Ono, T. Ohguro, S. Nakamura, M. Satio and Iwai, (1996) "1.5nm direct-tuneling gate oxide Si MOSFETs", IEEE Trans. Electron Devices, Vol.43, No. 8, pp. 1233-1242.

[11] Z. Liu and V. Kursun, (2006) "Leakage biased PMOS sleep switch dynamic circuits", IEEE Trans. Circuits Syst. II, Exp. Briefs, Vol. 53, No. 10, pp. 1093-1097.

[12] J. Kao, (1999) "Dual threshold voltage domino logic", in Proc. of the European Solid-State Circuits Conference, pp. 118-121.

[13] V. Kursun and E.G. Friedman (2006) Multi-voltage CMOS Circuit Design, Hoboken, NJ: Wiley.

[14] Farshad Moradi and Ali Peiravi, (2005) "An Improved Noise-Tolerant Domino Logic Circuit for High Fan-in Gates”, Proc. IEEE, pp. 116-121.

[15] M. C. Johnson, D. Somasekhar, L. Y. Chiou, and K. Roy, (2002) "Leakage control with efficient use of transistor stacks in single threshold CMOS", IEEE Trans. VLSI Syst., Vol. 10, pp. 1-5.

[16] S. Narendra, S. Borkar, V. De, D. Antoniadis, and A. P. Chandrakasan,(2001) "Scaling of stack effect and its application for leakage reduction”, IEEE ISLPLED, pp. 195-200.

[17] S. Sirichotiyakul, T. Edwards, C. Oh, R. Panda, and D. Blaauw, (2002) "Duet: An accurate leakage estimation and optimization tool for dual-Vt circuits”, IEEE Trans. VLSI Syst., Vol. 10, pp. 79-90.

[18] Predictive Technology Model (PTM), http://www.eas.asu.edu/ ptm.

[19] J. Wang, N. Gong, L. Hou, et al., (2008) "Low power and high performance dynamic CMOSXOR/XNOR gate design”, Microelectronics Engineering, Vol. 88, No. 8, pp. 2781-2784.

[20] J. Wang, N. Gong, L. Zuo, et al., (2010) "Performance estimation for dual threshold domino OR and the analysis for its availability under process variation”, Chinese J Electron, Vol. 38, pp.2611-2615. 
International Journal of VLSI design \& Communication Systems (VLSICS) Vol.4, No.1, February 2013

\section{Authors}

Tarun Kumar Gupta received the B.Tech degree in Electronics and Communication Engineering in 2001, M.Tech. degree in digital systems in 2003, and pursuing for Ph.D. degree. Currently, he is working as Assistant Professor in Electronics and Communication Engineering in MANIT, Bhopal, India. His fields of interest are VLSI design. His research mainly includes high speed and low VLSI circuits. He has nearly 06 publications in various international conferences and journals.

Kavita Khare received the B.Tech degree in electronics and communication engineering in 1989, M.Tech. degree in digital communication systems in 1993, and the Ph.D. degree in the field of VLSI design in 2004.Currently, she is working as Associate Professor in Electronics and Communication Engineering in MANIT, Bhopal, India. Her fields of interest are VLSI design and communication systems. Her research mainly includes design of arithmetic circuits and various communication algorithms related to synchronization, estimation and routing. She has nearly 110 publications in various international conferences and journals. Dr. Khare is a Fellow of IETE (India) and a Life Member of ISTE.
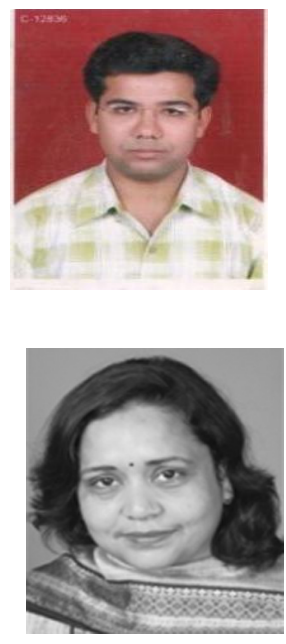